J. Clin. Chem. Clin. Biochem.

Vol. 19, 1981, pp. 265-266

\title{
Elimination of Low Molecular Weight Polyethylene Glycol 400 in the Urine Following an Oral Load, as a Measure of Intestinal Permeability
}

\author{
By J. G. Blätzinger, K. Rommel † and R. Ecknauer \\ Department of Clinical Chemistry; University of Ulm
}

(Received September 15/December 9, 1980)

Summary: After an oral load of $10 \mathrm{~g}$ polyethylene glycol, its concentration in the urine was measured by gas chromatography. The coefficient of variation of the imprecision between run was about $11 \%$. The urinary excretion was $25 \%$ of the administered dose with a coefficient of variation of the interindividual variation of $26 \%$ and the intraindividual variation between $13 \%$ and $29 \%$.

\section{Die Messung des niedermolekularen Polyethylenglycols im Urin nach oraler Gabe als Test zur Erfassung der intestinalen Permeabilität}

Zusammenfassung: Nach oraler Verabreichung von $10 \mathrm{~g}$ Polyethylenglycol wurde dessen Konzentration im Urin mittels Gaschromatographie gemessen. Der Variationskoeffizient der Variation von Tag zu Tag betrug rund 11\%. Im Urin wurden etwa 25\% der verabreichten Dosis ausgeschieden. Der Variationskoeffizient für die interindividuelle Streuung betrug $26 \%$, der für die intraindividuelle Streuung lag zwischen $13 \%$ und $29 \%$.

\section{Introduction}

The introduction of a mixture of polymers of ethylene glycol with an average molecular weight of approximately 400 (polyethylene glycol 400) by Chadwick et al (1977) offered the opportunity to measure, in one step, the permeability of the intestinal tract to molecules of different sizes. In the present communication we submitted the gas chromatographic measurement of polyethylene glycol 400 to the requirements of quality control. Furthermore we estimated the biological variation of polyethylene glycol 400 excretion into the urine.

\section{Material and Methods}

Polyethylene gly col 400 (Merck=Schuchhardt, München), pentaerythritol (Sigma, München), pentaerythritol tetraacetate (Ferak, Berlin), analytical grade mixed bed resin (AG 501-X8, D, 20-50 mesh, Biô-Rad, München), glacial acetic acid, acetone and perchloric acid (all from Merck, Darmstadt), acetic anhydride (Fluka, Buchs) and methylene chloride (Riedel de Haen, Hannover) were of analytical grade and of the highest purity level available. The measurements were made on the gas chromatograph $900-F$ using prepacked glass columns, $1.8 \mathrm{~m}$ in length and $2.00 \mathrm{~mm}$ in diameter. These were packed with $1 \%$ poly-S-179 on gas chrom Q 100/120 meșh (Perkin Elmer, Uberlingen).

The extraction of the urine and gas chromatography were carried out as described by Chadwick et al (1977) with the following modifications. We added pentaerythritol as opposed to the tetracetate in a concentration of $5 \mathrm{~g} / 1$ as opposed to $0.5 \mathrm{~g} / \mathrm{l}$.
The use of pentaery thritol tetraacetate always resulted in distorted, unreliable peaks of the internal standard with splitting and shifting of the peaks. This did not occur when using pentaerythritol.

The control specimen used in this study was prepared from urine to which polyethylene glycol 400 was added to give a concentration of $6.0 \mathrm{~g} / \mathrm{l}$

This urine was subjected to the same treatment as the samples of the volunteers.

After an overnight fast between 07:00 and 08:00 each of the 17 healthy volunteers took $10 \mathrm{~g}$ of polyethylene glycol 400 together with water. One hour later they received a standard breakfast consisting of two cups of unsweetened coffee or tea together with two bread rolls. After 5 hours all urine was collected and stored at $4^{\circ} \mathrm{C}$ until extracted for analysis. Three of the volunteers were investigated five times, with an interval of at least 6 days between two tests in order to measure the intraindividual variation.

All data are expressed as arithmetic mean with standard deviation assuming a Gaussian distribution.

\section{Results}

In a first series of 21 consecutive days of analysis the concentration of polyethylene glycol 400 in the control specimen was measured as $5.94 \pm 0.61 \mathrm{~g} / 1$ (range 4.72-6.90). In the second series of 19 days of analysis during which all samples of the volunteers were measured, the concentration was recorded as $6.39 \pm 0.73 \mathrm{~g} / \mathrm{l}$ (range 5.41-7.64). At no time were the values of the 


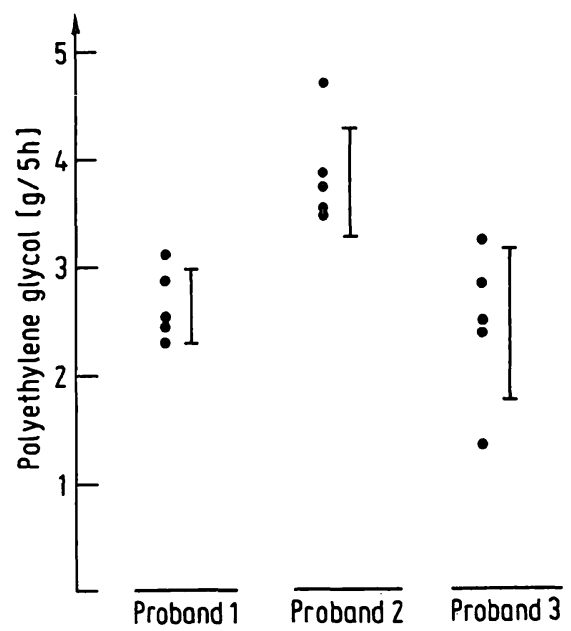

Fig. 1. Interindividual variation in the urinary excretion of orally administered polyethylene glycol.

Oral loading was carried out on 5 different days with intervals of at least 6 days inbetween. The individual results as well as the arithmetic mean with standard deviation are depicted.

control specimen during the second series of measurements outside the $\bar{x} \pm 3$ s range of the first series.

The excretion of polyethylene glycol 400 in the urine of the 17 volunteers was $2.54 \pm 0.66 \mathrm{~g} / 5 \mathrm{~h}$ (range $1.51-3.92)$. The interindividual variation thus was $26.3 \%$. A total of five tests were performed on three of the volunteers. They excreted $2.44 \pm 0.71 \mathrm{~g} / 5 \mathrm{~h}$ (range 1.45-3.25), $2.64 \pm 0.34 \mathrm{~g} / 5 \mathrm{~h}$ (range $2.31-3.11$ ) and $3.77 \pm 0.51 \mathrm{~g} / 5 \mathrm{~h}$ (range $3.51-4.74$ ). Thus the intrindividual variation was $29.2 \%, 12.8 \%$ and $13.6 \%$. A graphical depiction is given in figure 1.

The relative contribution of the different molecular weight polymers to the polyethylene glycol 400 was the same in the polyethylene glycol 400 added to the urine or used for oral dosage, and the polyethylene glycol 400 excreted into the urine (tab. 1).

\section{Discussion}

The measurement of the polyethylene glycol 400 using gas chromatography fulfills the requirements of quality control for measurements of substrates. The use of an integrator which does not assume a triangular shape for the peak based on height and width measurements (2) would improve the results as would correcting for the
Tab. 1. Distribution of the molecular weights in the native polyethylene glycol 400 and that excreted into the urine after an oral load.

\begin{tabular}{lll}
\hline & \multicolumn{2}{l}{ Fraction of total polyethylene glycol 400} \\
$M_{\mathbf{r}}$ & $\begin{array}{l}\text { Native polyethylene } \\
\text { gly } \infty 1 \text { ( } 400\end{array}$ & $\begin{array}{l}\text { "Excreted" poly- } \\
\text { ethylene glycol } 400\end{array}$ \\
\hline 242 & 0.029 & 0.022 \\
286 & 0.091 & 0.089 \\
330 & 0.174 & 0.196 \\
374 & 0.219 & 0.243 \\
418 & 0.208 & 0.193 \\
462 & 0.155 & 0.144 \\
506 & 0.087 & 0.079 \\
550 & 0.033 & 0.028 \\
594 & 0.005 & 0.006 \\
\hline
\end{tabular}

shift of the baseline. The present results tally with the results of Chadwick et al (1) in all but one respect. Unlike Chadwick et al. we did not ascertain preferential excretion of the low molecular weight polymers of the polyethylene glycol 400 into the urine. Since polyethylene glycol 400 is a linear molecule it might well be that within the range of the molecular weight of the polyethylene glycol 400 , the molecular weight of the polyethylene glycol does not determine the rate of permeation to a measurable degree. Compared to disaccharides such as cellobiose, lactulose and sucrose with a molecular weight of 342 , polyethylene glycol exhibits a rate of permeation which is about 50 times higher (1, 3-6; author's own unpublished results). Assuming that the high rate of permeation is due to the highly lipophilic nature of the polyethylene glycol 400 molecules, a major influence on the molecular weight of the individual polymers would not be expected. Furthermore it remains to be pointed out that the excretion into the urine is not solely dependent on the permeation of polyethylene glycol 400 though the gastrointestinal epithelium, but also its space of distribution in the body and the "permeability profile" of the kidney. Information on the latter is not yet available.

\section{Acknowledgement}

This study was supported by the "Deutsche Forschungsgemeinschaft" Bonn-Bad Godesberg (SFB 112 D 1).

4. Cobden, I., Dickinson, R. J., Rothwell, J. \& Axon, A. T. R. (1978), Brit. Med. J. II, 1060-1061.

5. Menzies, I. S. (1974), Biochem. Soc. Trans. 2, 1042-1047.

6. Weser, E. \& Sleisinger, M. H. (1965), Gastroenterology 48, $571-578$.

Dr. R. Ecknauer

Abteilung für Klinische Chemie

Universität Marburg

Uferstraße 2a

D-3550 Marburg/Lận 